\title{
Effect of Alloyed Hot-Dip-Galvanized Zinc Plating on Optimum Welding Conditions for Three-Layer Spot Welding
}

\author{
Souichiro Nishino* \\ Institute of Quantum Beam Science, Graduate School of Science and Engineering, Ibaraki University, Hitachi 316-8511, Japan
}

\begin{abstract}
In regard to spot welding of manufactured products like automotive parts, it is common practice to join three steel sheets having different grades and thicknesses and subjected to different kinds of surface processing. In such a case, it is more difficult to set the welding conditions than in the case of joining two sheets of the same grade and thickness. The present study aimed to determine by investigation the optimum welding conditions for spot-welded joints consisting of three stacked steel sheets of the sort supposed to be applied in fabricating actual auto components. Furthermore, the effect of zinc plating (i.e., hot-dip galvanizing) on the outer sheet on spot-welding characteristics-which is becoming a serious manufacturing problem - was investigated. According to the results of these investigations, as for a three-layer spot weld, the fused part of the welded joint (i.e., "nugget") is distorted to the high-tensile side. This distortion causes a difference in the resistance of the sheets, and the nugget is originated on the high-tensile side of the joint (which has higher resistance) and grows from that point of origin. Although two fracture modes are possible, namely, fracture in the base material or fracture in the weld nugget, fracture diameter and tensile shear strength have a proportional relationship in both cases regardless of the welding conditions. In the case that a zinc-plated (i.e., hot-dip zinc galvanized) steel sheet is used in the sheet stack, tensile shear strength falls and becomes more variable at low welding current. Accordingly, it is necessary to control the welding conditions so as to reduce that tensile-shear-strength variability. [doi:10.2320/matertrans.MT-M2020031]
\end{abstract}

(Received January 20, 2020; Accepted April 22, 2020; Published June 5, 2020)

Keywords: spot-welding, three-layer welding, high tensile strength steel, galvanized steel sheet, shear and plug type fracture

\section{Introduction}

In the manufacturing industry, particularly car making, as the strength of high-tensile steel used in car bodies continues to be improved, it is becoming necessary to revise welding equipment and facilities so that weld quality can be assured. Generally, in regard to the present state of affairs concerning spot welding of high- and ultra-high-tensile-strength steel sheet, the range of suitable conditions corresponding to high voltage, etc. is narrow, and setting the optimum welding conditions to secure adequate shear strength is a struggle. ${ }^{1,2)}$ As for car bodies, parts composed of three metal sheets, namely, an outer sheet (mainly composed of mild steel), a stiffener (mainly high-tensile steel), and an inner sheet (mainly ultra-high-tensile steel), joined by spot welding are common. A zinc-plated (i.e., hot-dip zinc-galvanized for rust proofing) steel sheet is often used as the outer sheet. Consequently, spot weldability is reduced by the effect of differences in strength and thickness of the sheets as well as by differences in surface-processing methods. Moreover, non-generation of weld-joint nuggets, blowholes and cracking around weld nuggets, and dispersion at nugget edges all become problems. ${ }^{3)}$

In light of the above-described problems, setting the optimum conditions for a spot weld joining three sheets is becoming more difficult. Furthermore, on performing welding tests with certain welding equipment on all possible sheet combinations, it is becoming necessary to do a huge number of tests on a vast amount of sheet combinations. A great many research papers concerning spot welding have been published. However, in the case of the bulk of them, the test samples were fabricated and spot welded in the form of two stacked steel sheets of the same material and thickness-which is a combination unlike that used in actual car bodies. ${ }^{4)}$

*Corresponding author, E-mail: souichiro.nishino.sn@vc.ibaraki.ac.jp
Given these circumstances, in the present study, the authors performed tests on the optimum welding conditions for a spot-welded joint between three stacked sheets of the type actually used in car body parts (namely, mild steel, hightensile steel, and ultra-high-tensile steel). In particular, we focused on the effect of a hot-dip-galvanized zinc plating (hereafter, simply "zinc plating") on the outer sheet (mild steel). That is to say, with steel grade and sheet thickness of the stiffener and inner sheet kept uniform, sheet combinations in which the presence or absence of the zinc plating on the third (i.e., outer) sheet is the only the difference between them were prepared and tested, and the influence of the zinc plating on the weld strength and welding conditions was investigated.

\section{Test Materials and Testing Method}

\subsection{Sheet combinations of test pieces}

Spot welding was performed on steel sheet (in combinations I and II listed in Table 1) supposed to be used in actual car-body parts. Sheet \#1 is composed of 780-MPa-class ultrahigh-tensile steel (supposed to be applied as the inner sheet), sheet \#2 is composed of 590-MPa-class high-tensile steel (stiffener), and sheet \#3 was composed of 270-MPa-class mild steel (outer sheet). However, in regard to sheet \#3, bare steel sheet (JSC270E) was used for sheet combination I, zinc-plated steel sheet (JAC270E) was used for combination II, and their influences on welding characteristics were

Table 1 Combination of steel sheets.

\begin{tabular}{|c|c|c|c|c|}
\hline \multirow{2}{*}{} & \multicolumn{2}{|c|}{$I$} & \multicolumn{2}{c|}{ II } \\
\cline { 2 - 5 } & Grade & Thickness $[\mathrm{mm}]$ & Grade & Thickness $[\mathrm{mm}]$ \\
\hline (1) & JSC780Y & 1.8 & JSC780Y & 1.8 \\
\hline (2) & JSC590R & 2.0 & JSC590R & 2.0 \\
\hline (3) & JSC270E & 0.8 & JAC270E & 0.8 \\
\hline
\end{tabular}


Table 2 Chemical compositions of steel sheets.

\begin{tabular}{|l|c|c|c|c|c|}
\hline & $C$ & $S i$ & $M n$ & $P$ & (Wt. \%) \\
\hline $\begin{array}{l}\text { JSC270E } \\
\text { JAC270E }\end{array}$ & 0.002 & 0.15 & 0.08 & 0.002 & 0.004 \\
\hline JSC590R & 0.07 & 0.08 & 1.87 & 0.017 & 0.002 \\
\hline JSC780Y & 0.08 & 0.65 & 2.03 & 0.015 & 0.001 \\
\hline
\end{tabular}

Table 3 Spot-welding condition.

\begin{tabular}{|c|c|}
\hline $\begin{array}{c}\text { Electrode diameter }[\mathrm{mm}] \\
\text { (Tip diameter }[\mathrm{mm}] \text { ) }\end{array}$ & $\begin{array}{c}16 \\
(6)\end{array}$ \\
\hline Pressing force $[\mathrm{kN}]$ & $2 \sim 4$ \\
\hline Welding current $[\mathrm{kA}]$ & $6 \sim 12$ \\
\hline Welding time [cycles] & 16 \\
\hline
\end{tabular}

experimentally evaluated and compared. The chemical compositions of all steel sheets were indicated in Table 2.

\subsection{Welding conditions}

In this study, spot-welding equipment with single-phase $\mathrm{AC}$ generator was used. The test pieces were prepared through combinations of applied force (in the range of 2 $4 \mathrm{kN})$, welding current $(6-12 \mathrm{kN})$, and welding time (i.e., 16 weld cycles, at which rate of increase in tensile shear strength is highest) as listed in Table 3.

\subsection{Tensile-test method}

The test pieces were formed by welding three $100 \times$ 40-mm steel sheets together in the T-shape form shown in Fig. 1. In the case of the target of this study, namely, spot welding of three stacked sheets, as measurement points for tensile shear strength, two places were chosen i.e., between sheets \#1 and \#2 (hereafter, point \#1/\#2) and between sheets $\# 2$ and \#3 (hereafter, point \#2/\#3). Accordingly, for each sheet combination, two sorts of test pieces (one for sheets \#1 and \#2 and one for sheets \#2 and \#3) were fabricated and subjected to tensile testing to obtain the tensile shear strength.

\section{Test Results}

\subsection{Correlation between welding conditions and tensile shear strength}

The correlation between tensile strength and welding
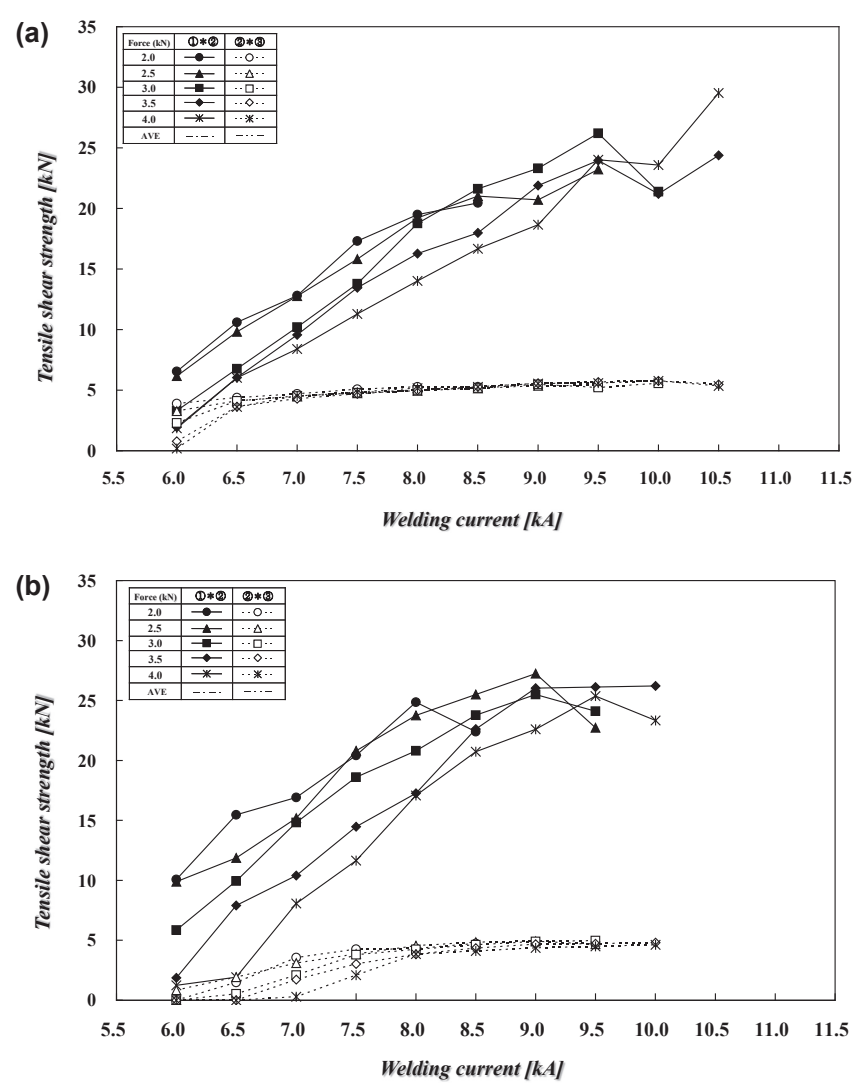

Fig. 2 Results of tensile tests: (a) Combination I; (b) Combination II.

conditions for sheet-combinations I and II are plotted in Figs. 2(a) and (b), respectively. The tensile shear strength at point \#1/\#2 rises with increasing welding current in the case of all welding forces. In contrast, as for point \#2/\#3, above a certain welding force, the tensile strength remains saturated even as welding current increases. These trends are the same in the case of both sheet combinations.

With welding current plotted on the horizontal axis and welding force plotted on the vertical axis, Fig. 3 shows the tensile shear strength for various welding conditions. Weld strength specified in Japanese Industrial Standard (JIS) Z3140 is $19.04 \mathrm{kN}$ for point \#1/\#2 and $3.53 \mathrm{kN}$ for point $\# 2 / \# 3$. The bold-line polygons in the figures enclose the weld strengths that satisfy JIS Z3140; in other words, they indicate the optimum welding conditions. Moreover, the regions on the left of the optimum regions indicate conditions that produce lack of weld strength, and the regions on the right indicate conditions that produce satisfactory weld
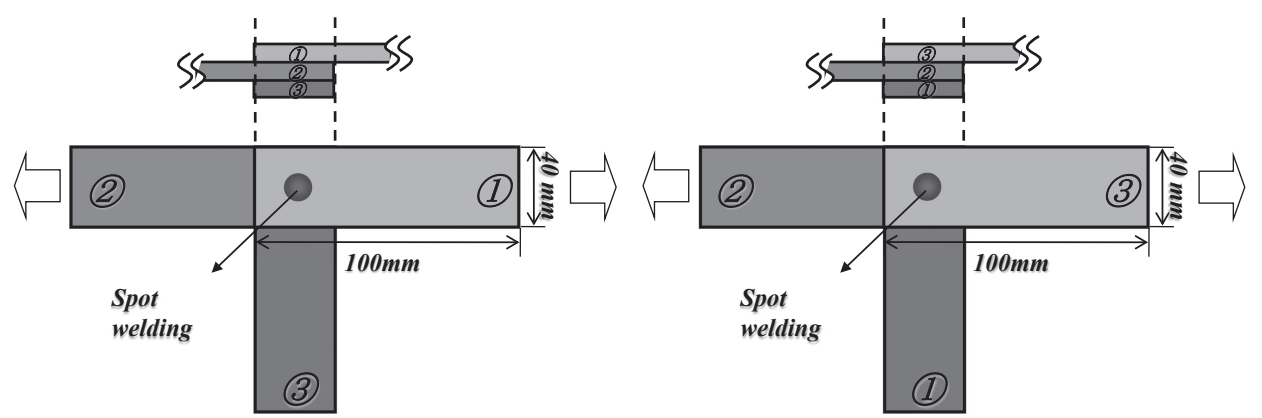

Fig. 1 Specimen for tensile test. 


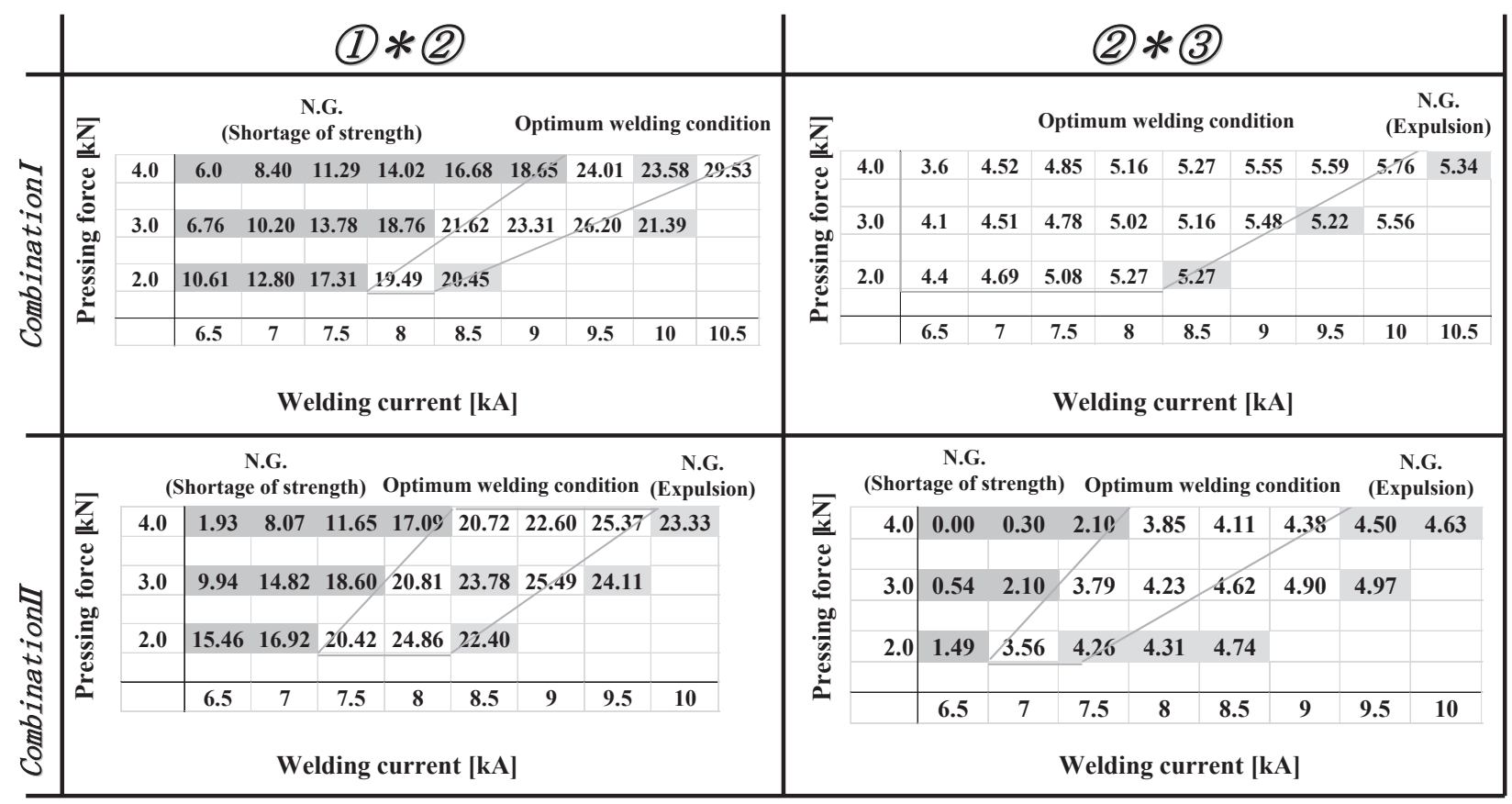

Fig. 3 Welding condition and tensile shear strength.

strength but "spatter" during welding. In other, both these regions result in improper welding.

In Fig. 3, as for point $\# 1 / \# 2$, the regions expressing optimum welding conditions vary little. On the other hand, as for point \#2/\#3, in the case that steel sheet \#3 is zinc-plated (i.e., sheet combination II) the region expressing optimumwelding conditions is much narrower than the region for bare steel sheet (i.e., sheet combination I). The difference between the tensile shear strengths due to the effect of the zinc plating on the sheet surface is clearly shown by these results.

\subsection{Observation of fracture morphology and nugget cross section}

According to the observation of the fracture morphology of the test pieces after tensile testing, the fracture morphology at point \#1/\#2 is shear fracture whereby the weld nugget shears at the joint face in the manner shown in Fig. 4(a). ${ }^{5}$ As for point \#2/\#3, however, "plug" fracture-namely, fracture from the base metal as shown in Fig. 4(b)—occurs. ${ }^{6}$ In this manner, as for spot-welding of three-stacked layer, the fracture morphologies at points $\# 1 / \# 2$ and $\# 2 / \# 3$ are different.

Since the fracture morphology is related to the nugget form between the sheets, cross-sectional observation of weld joints was performed. A cross-sectional image of a nugget is shown in Fig. 5. Image (a) represents the optimum conditions for sheet combination II (i.e., welding force: $3 \mathrm{kN}$; welding current: $8.0 \mathrm{kA}$ ), image (b) represents the insufficientstrength region (i.e., welding force: $3 \mathrm{kN}$; welding current: $6.5 \mathrm{kA}$ ), and image (c) represents dispersion-occurrence conditions for sheet combination II (i.e., welding force: $3 \mathrm{kN}$; welding current: $9.5 \mathrm{kA}$ ).

In the case of all the welding-condition regions, the nuggets are formed disproportionably toward the high-tensile side (i.e., inner sheet and stiffener). As for point \#1/\#2, since (a)

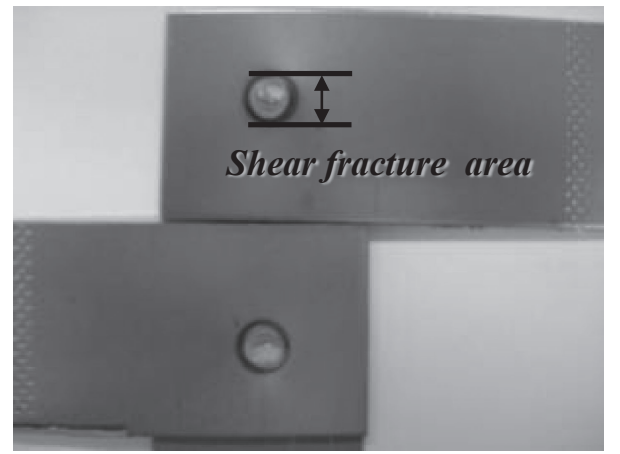

(b)

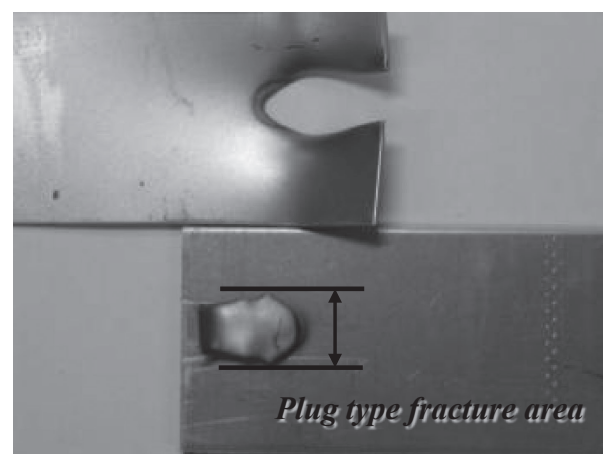

Fig. 4 Fracture mode on spot-welding area after tensile test: (a) Shear type fracture; (b) Plug type fracture.

the combination consists of similar high-tensile steel sheets, the resistance of the sheets is higher than that in the case of the combination with the mild-steel plate. Since the resistance and heating value of steel sheet have a proportional relationship, the nugget develops toward the high-tensile side from its point of origin. In contrast, the joint at point \#2/\#3 is at the edge of the nugget, and under certain conditions, the nugget may not be generated. The difference between 
(a)

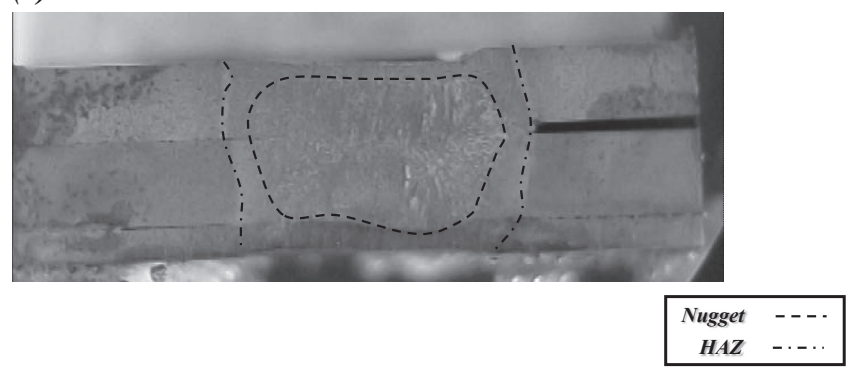

(b)

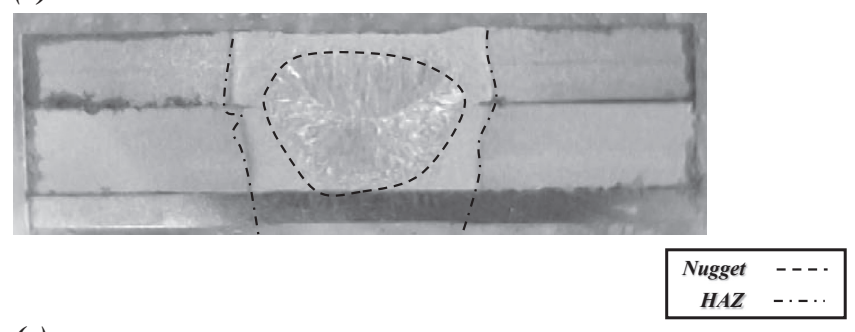

(c)

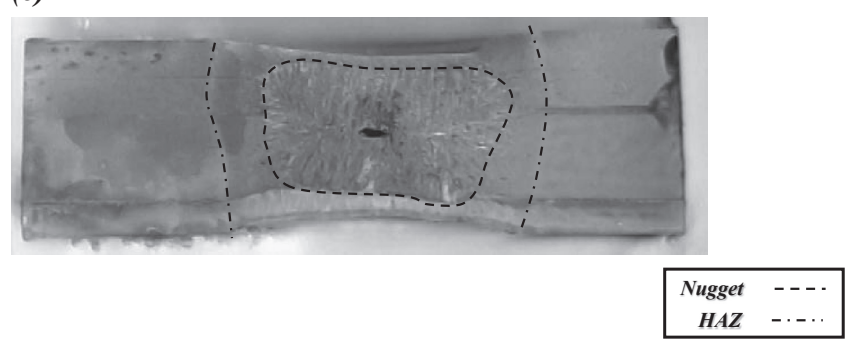

Fig. 5 Morphologies of spot-welding cross section: (a) Force $3 \mathrm{kN}$ Welding current $8.0 \mathrm{kA}$; (b) Force $3 \mathrm{kN}$ Welding current $6.5 \mathrm{kA}$; (c) Force $3 \mathrm{kN}$ Welding current $9.5 \mathrm{kA}$.

the fracture morphologies can be understood in terms of the different formations of nuggets at points $\# 1 / \# 2$ and \#2/\#3.

\section{Discussion}

\subsection{Unified evaluation of tensile shear strength}

Strength assurance concerning spot welds is given in terms of tensile shear strength and plug fracture diameter. However, in this study, for the test pieces, comparatively thick hightensile steel was used for sheets \#1 and \#2. As a result, in the case of tensile shear tests, the ratio of the nugget diameter to sheet thickness becomes small, so plug fracture in the base metal does not occur; instead, shear fracture inside the nugget occurs. ${ }^{7,8)}$ Given that fact, we measured the diameter of the shear-fracture area of the nugget (hereafter, "shear-fracture diameter").

The relationship between shear-fracture diameter and tensile shear strength is plotted in Fig. 6(a). In the graph, a proportional relationship between shear-fracture diameter and tensile shear strength is shown regardless of welding conditions.

Moreover, we evaluated the diameter of the plug fracture between sheets \#2 and \#3. The relationship between plugfracture diameter and tensile shear strength is plotted in Fig. 6(b). In the figure, a proportional relationship between plug-fracture diameter and tensile shear strength is shown. However, the scatter of the data in the plug-fracture case
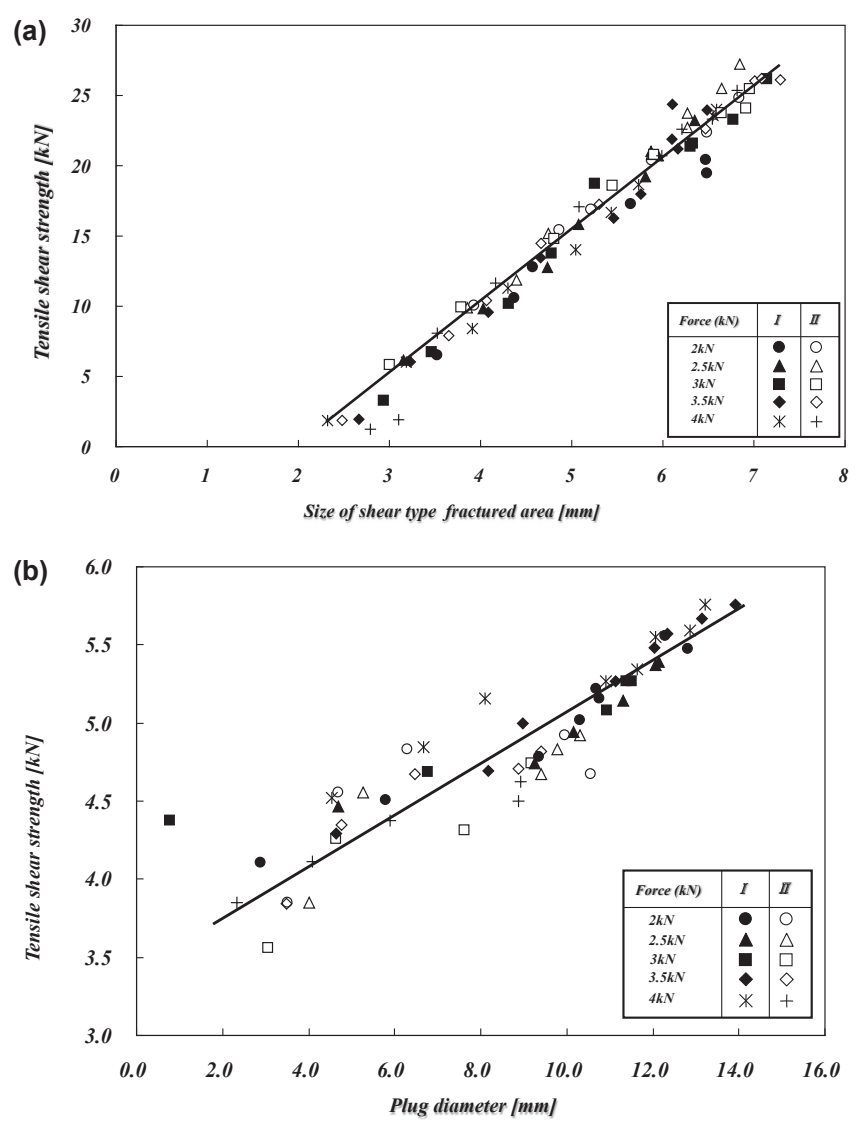

Fig. 6 Evaluation of tensile shear strength on spot-welding: (a) Shear type fracture; (b) Plug type fracture.

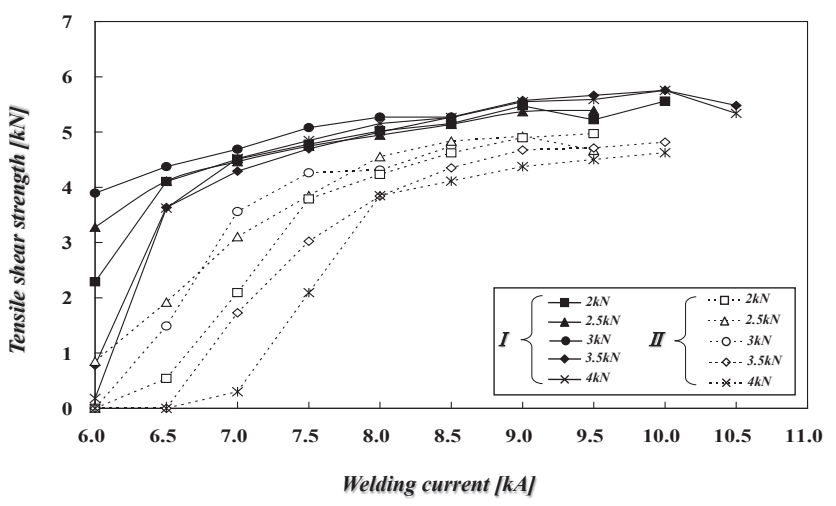

Fig. 7 Effect of galvanization on tensile shear strength.

[Fig. 6(b)] is greater than that in the shear-fracture case [Fig. 6(a)].

According to the results in Figs. 6(a) and (b), it is possible to uniformly evaluate the tensile shear strength between sheets \#1 and \#2 in terms of shear-fracture diameter and that between sheets \#2 and \#3 in terms of plug-fracture diameter regardless of welding conditions.

\subsection{Effect of zinc plating}

The results of tensile tests for point \#2/\#3 in combinations I and II are arranged in Fig. 7. According to this figure, in the case that the zinc plating was applied to the outer sheet, tensile shear strength falls by $10 \%$ to $20 \%$, and the suitable range becomes narrower. In particular, the scatter is bigger on the low-voltage side. 


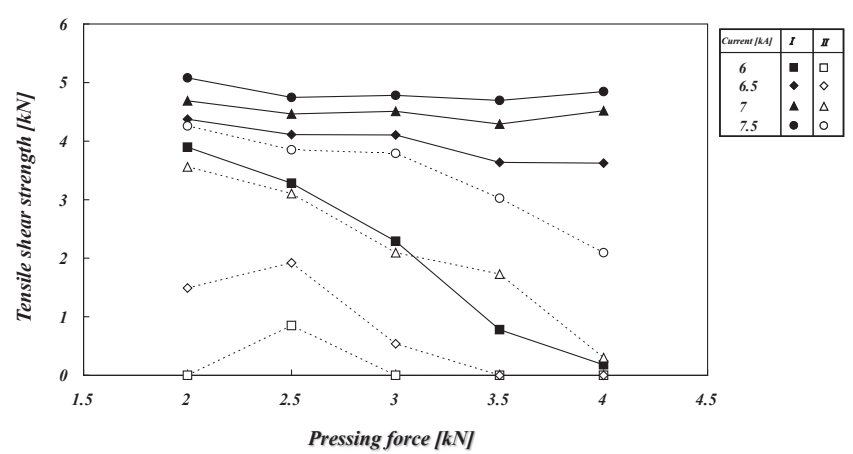

Fig. 8 Tensile shear strength in low current region.

Figure 8 shows the relationship between welding force and tensile shear strength at \#2/\#3 for the low-voltage region (6 to $7.5 \mathrm{kA})$. In the case of the zinc-plated outer sheet, regardless of welding force, strength in the low-voltage region cannot be assured, and scatter of the strength data is large.

In regard to spot welding of the plated steel plate, as shown in Fig. 9, the zinc plating between the steel plates melts and spreads out during the initial stage of current flow. After that, when the area over which current flows increases, current density drops considerably. ${ }^{9,10)}$ Given that fact, the authors believe that the growth of the region that melts and joins (i.e., the weld nugget) is restricted and, thereby, the joint strength is lowered and becomes more scattered. Consequently, in the case of spot welding of zinc-plated steel sheets, welding conditions that produce low tensile-shear-strength scatter (for example, applying a high welding current) must be selected.

\section{Conclusion}

In regard to spot-welded joints between three stacked steel sheets (of the kind supposed to be used for car bodies), this study aimed to determine the optimum welding conditions by investigation and to uniformly evaluate the tensile shear strength of the joints. Moreover, the effect of zinc plating on outer sheet on spot-welding characteristics was investigated. The results of this study are summarized in the following three points.

(1) In the case of a three-layer spot weld, the weld nugget is formed disproportionably toward the high-tensilesteel side (namely, the side with the stiffener). This disproportionate growth is the cause of a difference in resistances of the steel sheets. Since the resistances of the steel sheets and the heat-release value have a proportional relationship, the nugget originates on the high-tensile side (which has higher resistance) and grows from that point.

(2) As for sheet group \#1/\#2, the failure mode is shear fracture, and tensile shear strength is proportional to shear-fracture diameter. In addition, as for sheet group $\# 2 / \# 3$, the failure mode is plug fracture, and tensile shear strength is proportional to plug-fracture diameter. Tensile shear strength can be uniformly evaluated according to fracture diameter regardless of sheet combination or welding conditions. Furthermore, these proportional relationships show little data scatter in the case of shear fracture; however, in the case of plug fracture, the scatter is considerable. Accordingly, as for the plug-fracture section, responses such as increasing the frequency of verification are needed.

(3) In the case that zinc plating is applied to the outer sheet, current density decreases owing to melting of the plating between the sheets and growth of the molten weld nugget in the joint is inhibited. As a result, tensile shear strength falls by 10 to $20 \%$ and becomes more variable at low welding currents.

\section{REFERENCES}

1) W. Noh, W. Kim, X. Yang, M. Kang, M. Lee and K. Chung: Int. J. Mech. Sci. 121 (2017) 76-89.

2) H. Zhang, X. Qiu, F. Xing, J. Bai and J. Chen: Mater. Des. 55 (2014) $366-372$.

3) S.M. Darwish and A.M. Al-Samhan: J. Mater. Process. Technol. 147 (2004) 51-59.

4) M. Pouranvari, S.M. Mousavizadeh, S.P.H. Marashi, M. Goodarzi and M. Ghorbani: Mater. Des. 32 (2011) 1390-1398.

5) X. Sun, E.V. Stephens and M.A. Khaleel: Eng. Fail. Anal. 15 (2008) 356-367.

6) N. Becker, J. Gilgert, E.J. Petit and Z. Azari: Mater. Sci. Eng. A 596 (2014) 145-156.

7) H. Zhang, A. Wei, X. Qiu and J. Chen: Mater. Des. 54 (2014) 443-449.

8) H. Zhang, X. Qiu, Y. Bay, F. Xing, H. Yu and Y. Shi: Mater. Des. 63 (2014) 151-158.

9) Y. Luo, J. Liu, H. Xu, C. Xiong and L. Liu: Mater. Des. 30 (2009) 2547-2555.

10) S.S. Rao, R. Chhibber, K.S. Arora and M. Shome: J. Mater. Process. Technol. 246 (2017) 252-261.
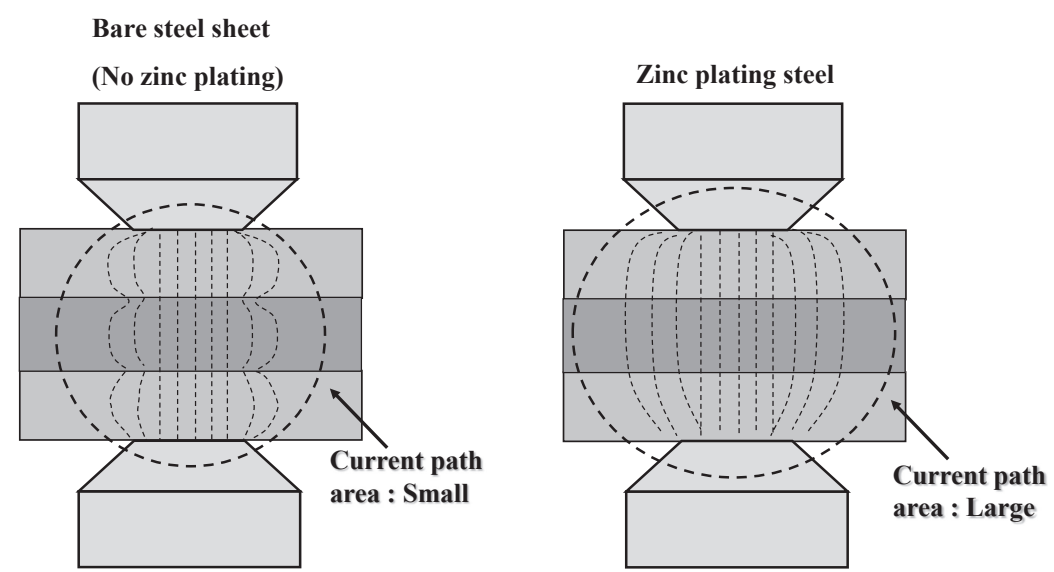

Fig. 9 Influence of zinc plating on current path in spot welding. 